\title{
Pachydermoperiostosis mimicking the acral abnormalities of acromegaly
}

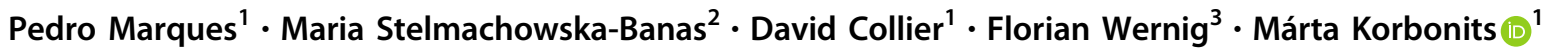

Received: 3 November 2019 / Accepted: 18 December 2019 / Published online: 8 January 2020

(c) The Author(s) 2020

Bones and soft tissues of hands and feet can be affected by different conditions, including genetic, metabolic or systemic disorders [1]. Acromegaly is a condition caused by excessive secretion of growth hormone (GH) leading to elevated insulin growth factor-1 (IGF-1) levels, which is characterised by somatic overgrowth and physical disfigurement notably affecting hands and feet [2]. However, there are other conditions that can mimick the clinical features seen in acromegaly without GH/IGF-1 anomalies, termed as pseudoacromegaly [1].

A 3-year-old boy was noted to have large hands and feet, severe joint pain and hyperhidrosis. Later he developed forehead skin furrowing (pachydermia), but was not diagnosed until the age of 26 , when he was referred to an endocrinologist with the suspicion of acrogigantism. IGF-1 level was not elevated, random $\mathrm{GH} 0.14 \mu \mathrm{g} / \mathrm{l}$, GH after glucose-load was $0.46 \mu \mathrm{g} / \mathrm{l}$. He has pachydermoperiostosis due to a homozygous HPGD (15-hydroxyprostaglandindehydrogenase) mutation (c.175-176delCT). His hands and feet are remarkably large and fleshy with long and thickened fingers and toes, prominent digital clubbing and loss of the normal contour of the widened wrists and ankles (Fig. 1, left subject). Similar acral features can be seen in acromegaly (Fig. 1, middle subject), while both are remarkably different from a healthy male (Fig. 1, right subject). The left patient had other clinical features characteristic of pachydermoperiostosis, including seborrhoea, long eyelashes,

Márta Korbonits

m.korbonits@qmul.ac.uk

1 Centre for Endocrinology, William Harvey Research Institute, Barts and the London School of Medicine and Dentistry, Queen Mary University of London, London EC1M 6BQ, UK

2 Department of Endocrinology, Centre of Postgraduate Medical Education, Warsaw 01-809, Poland

3 Endocrinology, Imperial College Healthcare NHS Trust, London W6 8RF, UK blepharoptosis, peri-articular oedemas, synovial effusions and periodic watery diarrhoea. Although tall stature is not a classical feature of pachydermoperiostosis [3], this patient's height $(200 \mathrm{~cm}$, midparental-height $181 \mathrm{~cm})$ adds further diagnostic challenges to distinguish from young-onset acromegaly. His brother presented at the age of 3 with arthralgia and bone and skin manifestations; he carries the same homozygous mutation, while parents are heterozygous.

Pachydermoperiostosis (primary autosomal recessive hypertrophic osteoarthropathy) is a rare condition characterised by digital clubbing, joint problems and pachydermia, but other skin manifestations due to dermal and sebaceous gland hypertrophy can be found [1]. HPGD loss leads to accumulation of circulating prostaglandins, suggested to play a role in the development of the characteristic signs and symptoms [3]. Pachydermoperiostosisrelated acral abnormalities may overlap with those seen in acromegaly, including broadened extremities, widened, thickened and stubby fingers, and thickened soft tissue. In acromegaly, excessive GH/IGF-1 leads to periosteal bone formation, growth of synovial tissue, cartilage and leading to hypertrophic arthropathy associated with pain and deformity [2], as also seen in pachydermoperiostosis. Cutis verticis gyrate, facial coarsening, hyperhidrosis, seborrhoea and acne are common in pachydermoperiostosis as well as in acromegaly. However, other manifestations characteristic in pachydermoperiostosis, but not seen in acromegaly, are blepharoptosis, long eyelashes, myelofibrosis, hypoalbuminemia, peptic ulcer, gastric cancer or watery diarrhoea in response to certain triggers, such as cold drinks, greasy food or sexual activity [1]. Pachydermoperiostosis diagnosis is often established by geneticists or rheumatologists; however, these patients may be first referred for investigation of possible $\mathrm{GH}$ excess to an endocrinologist, as in our case and in several cases reported in the literature, thus we should be aware of pachydermoperiostosis as a pseudoacromegaly condition and aid in establishing its diagnosis [1]. 
Fig. 1 Hands, feet and facial appearance of a tall patient with pachydermoperiostosis (left subject), in comparison with a patient with acromegaly (middle subject) and a healthy male (right subject). Note the digital clubbing and the loss of contour of the wrist and ankle in the patient with pachydermoperiostosis
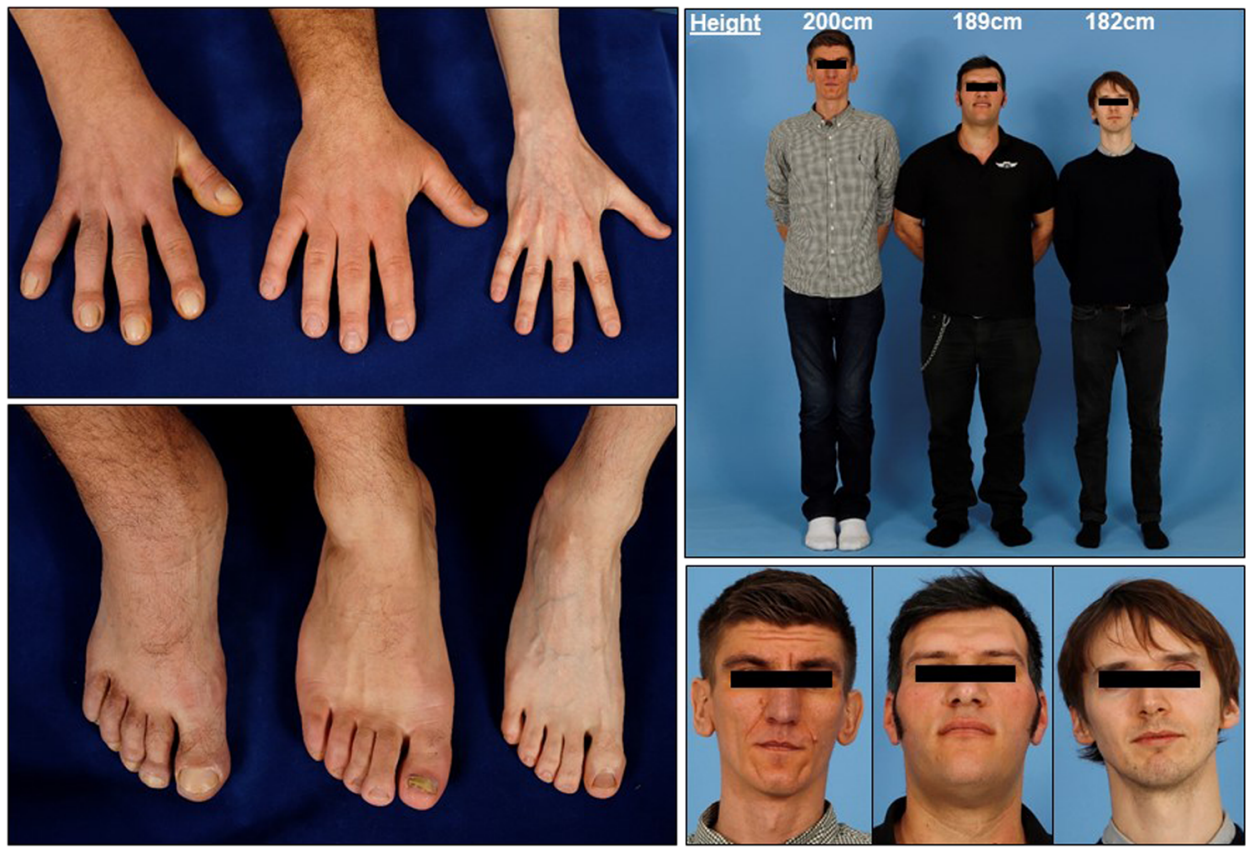

Acknowledgements We are grateful to the patients and the healthy individual for consenting the clinical photography and its publication. P.M. is supported by the Joan Adams Clinical Fellowship and the Barts and The London Charity Clinical Research Training Fellowship.

Author contributions P.M., M.S.-B., D.C., F.W. and M.K. were involved in the clinical care of the patient, literature review and manuscript preparation. All authors read and approved the final manuscript.

\section{Compliance with ethical standards}

Conflict of interest The authors declare that they have no conflict of interest.

Ethical approval Ethical approval was granted by the local Ethics Committee.

Informed consent Informed consent was obtained from all the patients included in this article.
Publisher's note Springer Nature remains neutral with regard to jurisdictional claims in published maps and institutional affiliations.

Open Access This article is distributed under the terms of the Creative Commons Attribution 4.0 International License (http://crea tivecommons.org/licenses/by/4.0/), which permits unrestricted use, distribution, and reproduction in any medium, provided you give appropriate credit to the original author(s) and the source, provide a link to the Creative Commons license, and indicate if changes were made.

\section{References}

1. P. Marques, M. Korbonits, Pseudoacromegaly. Front. Neuroendocrinol. 52, 113-143 (2019). https://doi.org/10.1016/j.yfrne.2018.11. 001

2. P. Chanson, S. Salenave, Acromegaly. Orphanet J. Rare Dis. 3, 17 (2008). https://doi.org/10.1186/1750-1172-3-17

3. Z. Zhang, C. Zhang, Z. Zhang, Primary hypertrophic osteoarthropathy: an update. Front Med. 7(1), 60-64 (2013). https://doi.org/10. 1007/s11684-013-0246-6 